\title{
Dispute over data privacy halts cancer study
}

David Cyranoski, Tokyo

The brakes have been slammed on a major cancer-research project, after the Japan Medical Association (JMA) accused its leaders of failing to provide adequate protection for participants' privacy.

The incident illuminates the distrust between physicians and clinical researchers in Japan which, observers say, continues to dog efforts to bolster the country's clinical research capacity.

The cancer project seeks to study the respective roles of lifestyle and genetics in determining susceptibility to major cancer types. Its planners want to collect blood samples, as well as information on diet, exercise and sleeping habits, from 100,000 subjects.

The project began in May with a survey of 6,000 citizens in Kumano-cho, a small town near Hiroshima. Project organizers planned to start taking blood samples in August.

But on 16 July, the Tokyo-based JMA, reacting to enquiries from Kumano-cho residents, sent a letter of complaint to the education ministry, which funds the project. The letter said that the project's data-collection process could not ensure that the personal information gathered would remain private.

"They were using ordinary citizens people who had no legal responsibility to protect the information - to go to people's

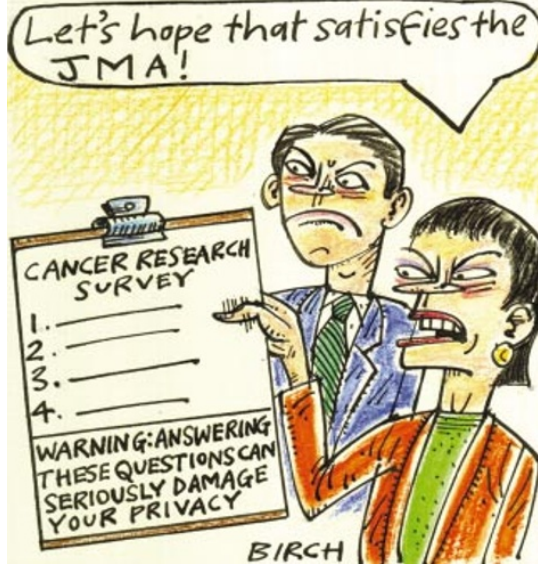

houses and collect it," says Rintaro Sawa, a member of the JMA's board of trustees. Sawa claims that the study took advantage of the fact that people in Hiroshima are used to answering such questions for radiationfallout studies.

The project's leaders have now told the education ministry that they will postpone the study for a year while they try to find a new way of collecting the data. One of the project leaders, Kei Nakachi, a cancer epidemiologist at the Radiation Effects Research Foundation in Hiroshima, says he accepts the JMA's critique. "We want to be honest and open and look at our problems," he says.

But some researchers are perplexed by the watchdog role that the JMA seems to be assuming over their work. The JMA says it has no choice, as a law enacted in May last year to ensure the security of personal information fails to require researchers to monitor their own procedures (see Nature 417, 689; 2002). "There's no one else to do it," says Sawa. From August, the JMA will establish a committee to oversee the use of personal information and medical samples in research.

The JMA is also monitoring a project to create a database of genetic information using 300,000 samples from patients who suffer from various diseases or drug sideeffects (see Nature 423, 209; 2003).

Yusuke Nakamura, a genomicist at the University of Tokyo and that project's leader, says he plans to spend $¥ 8$ billion (US\$70 million) of the project’s $¥ 20$-billion five-year budget on proper methods for collecting and storing data, including the establishment of computer firewalls to protect the data, and training of medical professionals to collect samples.

But Nakamura worries that the JMA's aggressive stance on privacy will make participants uneasy, and scare them away from his study. "We have been very careful. I don't want to lose the patients' trust," he says.

\section{African project seeks model solution to water shortage}

\section{Quirin Schiermeier, Munich}

Water supply is one of the toughest issues facing the world's poorest countries. But an innovative project in West Africa could offer a way forward, according to hydrologists involved in the scheme.

German and Ghanaian researchers are working together to create a model of how meteorological, environmental, social and economic variables affect the Volta basin. By 2006, they hope to be able to use the model to make practical decisions about water management in the region.

The Volta basin comprises parts of Ghana, Burkina Faso and several adjacent countries. Agriculture is the main source of income in this area, and population growth is now putting pressure on land and water resources.

The scheme is part of the GLOWA (Global Change in the Hydrological Cycle) initiative, set up by the German government in 2001 to improve water management in several different river catchments. Other pilot studies are taking place on the Elbe and Danube rivers in Germany, the Jordan River Basin, the Wadi Drâa in
Morocco and the River Ouémé in Benin. In the first phase of the Volta project, researchers assessed the water flows and patterns across the Volta basin. In the second phase, they plan to use this information to build a model that will enable local planners to assess the impact of their actions on water management, agriculture, ecology and power supply. The German government this month approved $€ 10$ million (US\$11.3 million) to support this second stage.

"This is the most comprehensive science-led approach ever tried in West Africa to guarantee the effective allocation of water resources," says Daniel Adom, a water engineer and executive secretary of the Ghanaian Water Resources Commission (WRC).

"We envisage a smart scientific toolbox for modelling, at different scales, the likely impact of different water-management options on power production, industry, agriculture and human health," says GLOWA Volta's scientific coordinator, Nick van de Giesen, a hydrologist at the Center for Development Research at the University of Bonn in Germany.

Looming water crises were the subject of the 3rd World Water Forum in Japan (see Nature 422, 251-256; 2003). But experts think that the real action will take the form of relatively small initiatives, targeted at specific river basins.

Ghana, with its relatively strong scientific infrastructure and stable political system, is an ideal location for the project, van de Giesen says. The country has decades of experience with major water projects, and the dam on the river at Lake Volta supplies most of its electricity. But the growing population and a shortening rainfall season mean that Ghanaians are drawing off more of the river's flow for household use and for farm irrigation, which is relatively new in the region.

This pressure has led to growing political conflict over the use of water, leading the WRC to revise its water-management and regulation practices in the Volga basin. But, says van de Giesen, "the knowledge base is narrow - and that's where GLOWA Volta comes in".

www.glowa-volta.de 